\title{
Postharvest Loss Assessment of Tomato (Solanum lycopersicum L.) in Fogera, Ethiopia
}

\author{
Fentahun Asrat $^{1, \text { a }}$, Asrat Ayalew ${ }^{1, b, *}$, Asfaw Degu ${ }^{2, c}$ \\ ${ }^{1}$ Department of Horticulture, College of Agriculture and Environmental Science, University of Gondar, 196 Gondar, Ethiopia \\ ${ }^{2}$ Department of Plant Sciences, College of Agriculture and Environmental Science, Bahir Dar University, 79 Bahir Dar, Ethiopia \\ * Corresponding author
}

\begin{tabular}{|c|c|}
\hline A R T I C E I N F O & A B S T R A C T \\
\hline $\begin{array}{l}\text { Keywords: } \\
\text { Postharvest loss } \\
\text { Ethiopia } \\
\text { Tomato } \\
\text { Quality } \\
\text { Market chain }\end{array}$ & $\begin{array}{l}\text { Valuation of postharvest loss and identification of its causes enables to develop proper measures } \\
\text { required to reduce losses. The study was conducted at "Fogera" District, South Gondar, Ethiopia } \\
\text { between } 2017 \text { and } 2018 \text { years to assess the extent of postharvest loss of tomato (Solanum } \\
\text { lycopersicum L.) and to identify major causes with respective handling system. In this study, a total } \\
\text { of } 125 \text { farmers and } 40 \text { traders ( } 10 \text { wholesalers and } 30 \text { retailers) were involved as main respondents. } \\
\text { Data collection was done using semi structured interview schedule, key informant interview, focus } \\
\text { group discussion and observation. Besides respondents estimation, a sample analysis was conducted } \\
\text { to estimate the extent of postharvest loss as per the FAO minimum quality standards. Descriptive } \\
\text { statistics such as average, percentage, frequency and standard deviation were used to analyse data } \\
\text { and tables, graphs and charts were used to present result. Result revealed that almost half of tomato } \\
\text { produced is damaged and puts out of normal use with highest loss at producer level due to different } \\
\text { causes which are complex and interrelated across tomato market chain. Marketing situation, insect } \\
\text { pest and disease, lack of awareness, low economic status of producers, late harvesting, mechanical } \\
\text { damage during harvesting and transportation, poor quality of produce and price fall were some of } \\
\text { the reasons identified as major cause of post-harvest loss of tomato. For solving the postharvest loss } \\
\text { problems, actors in supply chain has to develop cooperation and effective communication among all } \\
\text { the research, extension, and industry personnel involved. }\end{array}$ \\
\hline
\end{tabular}

\section{Introduction}

In Ethiopia, vegetable subsector has a vital role in human nutrition and health, farm income generation, poverty alleviation and foreign currency earnings through export and foreign direct investment. Tomato (Solanum lycopersicum L.) is a widely grown vegetable crop in Ethiopia. High post harvest loss is considered as one of the major constraints in vegetable supply chain.

As estimated roughly, one-third of food produced for human consumption is lost or wasted globally, which amounts to about 1.3 billion tons per year (Vilariño et al., 2017; FAO, 2016). This inevitably also means that huge amounts of the resources used in food production and marketing are used in worthless.

Given the challenges posed by climate change and limited land and water resources, food security cannot be achieved merely through increases in agricultural productivity. Attention also needs to be given to reduce losses along the farm-to-consumer chain. Over $10.90 \%$ in the world and $23.2 \%$ of the population in sub-Saharan Africa are still suffering from hunger in the period 201416 (FAO, 2016). The ultimate goal of food loss and waste reduction improve food security for people while saving natural resources and energy (FAO, 2016).

To develop effective intervention strategies for postharvest losses reduction, it is important to understand the core logistics and quality control activities that could affect postharvest losses in these chains (Macheka et al., 2017). The 2007-2008 global food crises have renewed interest in postharvest loss, but estimates remain scarce, especially in Sub-Saharan Africa (Kaminski and Christiaensen, 2014). Most studies on post-harvest technology have so far concentrated on grains and other durable products, which are stored dry and a substantial technology has been developed to deal with these problems (Atanda et al., 2011). 
Generally, food supply can be induced either by increase in production or reduction of loss. Reducing postharvest loss of produce is key technique in improving food security for people while saving natural resources and energy (FAO, 2016). Ayandiji et al. (2011) reported that, with the reduction of postharvest losses by $50 \%$, food availability would be increased by $20 \%$ without cultivating an additional hectare of land for increasing crop yield. Furthermore, there have not been many researches undertaken on the impacts of food loss in developing countries (Ayandiji et al., 2011). Thus, there is an urgent need for further quantitative researches that provide postharvest loss estimates.

In developing countries like Ethiopia, most of postharvest losses occur before reaching the market. Little information is available regarding postharvest loss of perishable produces. Inefficient pre and postharvest handling practices, postharvest losses and major issues of food quality are becoming major challenges in food security (Emana et al., 2017). However, for applying any loss reduction techniques, major causes, extent and general postharvest system has to be identified at initial stage. Therefore, the main objective of this research was to assess the postharvest loss of tomato in case of Fogera district, South Gondar Zone, Amhara National Regional State, Ethiopia.

\section{Materials and Methods}

\section{Site Description}

The study was conducted in Fogera district which is located in South Gondar Zone, Amhara National Regional State, Ethiopia (Figure 1). It is one of the 126 districts in the region and has an area of 117.405 hectares divided administratively in to 32 Kebeles with a total population of 233.529. A total of 42.746 households are engaged in agriculture out of which about 21.018 are tomato producers. This area is suitable for fresh vegetable production due to its ample irrigation potential and easy access to near-by market places. The district is known for its plain topography where flat land accounted nearly $76 \%$. The mean annual rainfall is $1,216.30 \mathrm{~mm}$, with bimodal cropping seasons (Belg and Meher). Its altitude ranges from 1.774 up to $2.410 \mathrm{~m}$ allowing a favorable opportunity for wider crop production and livestock rearing. In 2016 about 5.606.875 hectare of land was covered with tomato and 168.206,25 ton of yield was obtained (FDOA, 2016).

\section{Sampling Technique and Size}

Two stage sampling technique was used to select tomato producers. First four tomato producing kebeles were identified through reviewing secondary data on production level with respective number of producers and area coverage from district agriculture office. Secondly respondent producers were selected from each kebele based on probability proportional to size of tomato producers and random sampling was implemented after selecting sample tomato producers as this research was focused only on tomato. A total of 125 farmers were considered from four kebeles, which was divided in to each kebele based on probability proportion of tomato producers. Additionally, total of 40 traders (10 wholesalers and 30 retailers) were selected by systematic random sampling from nearby towns.
The required sample size was determined by Cochran's (1977) proportionate to size sampling methodology; $\mathrm{n}=$ $\mathrm{Z}^{2} \mathrm{pq} / \mathrm{e}^{2}$, where; $\mathrm{n}=$ sample size; $\mathrm{Z}=$ confidence level $(\alpha=$ $0.05) ; \mathrm{p}=$ proportion of the population containing the major interest, $\mathrm{q}=1-\mathrm{p}$ and $\mathrm{e}=$ allowable error. Hence, $\mathrm{Z}=$ 1.96 (from the table), $\mathrm{p}=21.018 / 233.529=0.09$, then $\mathrm{q}$ $=0.91$ and $e=0.05$. This resulted in a sample population of 125 respondents for sample producers (Table 1). Sample size for traders was determined based on their amount and purposively by considering existence of similar value chain activities.

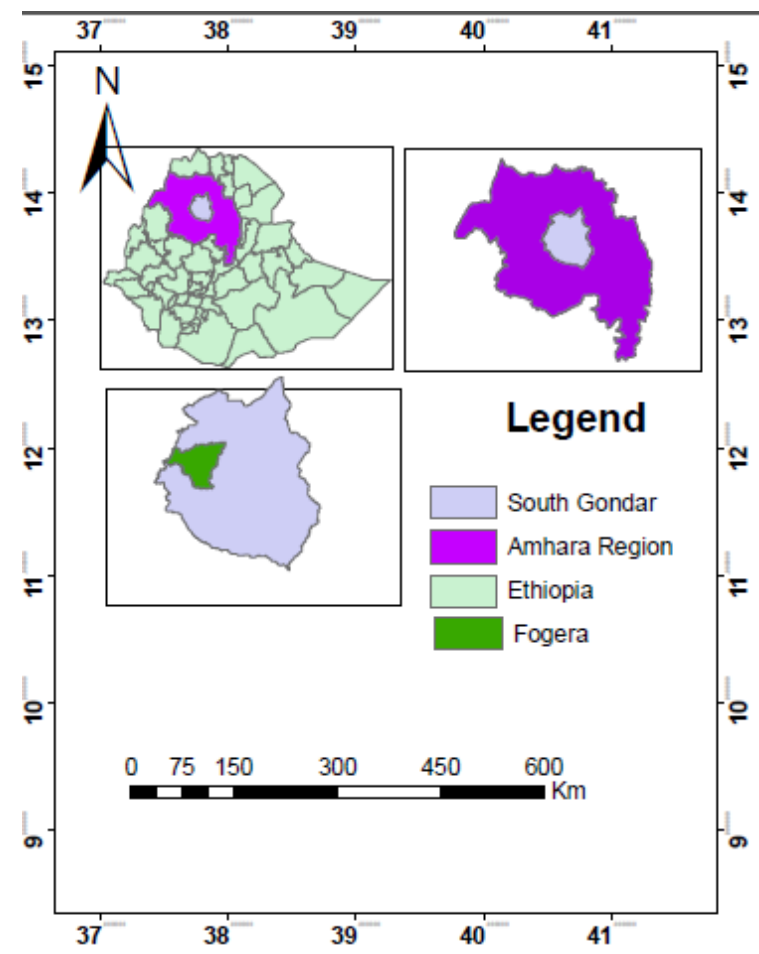

Figure 1 Map of the study area in Fogera, Ethiopia

Table 1 Distribution of sample producers across sample kebeles

\begin{tabular}{l|lcc}
\hline S.N & Sample kebeles & Number growers & Samples \\
\hline 1 & Shina & 870 & 42 \\
2 & Woreta Zuria & 792 & 38 \\
3 & Kuhar Abo & 645 & 31 \\
4 & Kuhar Micheal & 294 & 14 \\
\hline & Total & 2.601 & 125 \\
\hline
\end{tabular}

\section{Data Collection Method}

A semi-structured interview schedule was designed and used to collect primary data from tomato producers. Information's about issues such as tomato production, produce utilization, marketing, postharvest handling, transportation, postharvest losses and its management and factors causing postharvest losses with respective social, economic environmental and demographic description of respondents were covered. Interviews were done in local language (Amharic) in order not to create any language barrier. Key informant interview (KIIs) with regional research center experts (1), agriculture office managers (2), and development agents (DAs) at kebele level (6) was conducted to gather technical information in order to authenticate accuracy of information supplied by sample producers. 
Data were also collected using focus group discussion (FGDs), field observation. In the field observation, estimation of losses was conducted by taking known quantity of samples across supply chain in the research area. Some relevant data were gathered through examining secondary sources such as documents, reports and records maintained at the Office of DAs and District Office of Agriculture.

Physical fresh produce quality survey was conducted to determine the type, extent and causes of postharvest losses at the time of harvesting through observation. Tomato farms, harvesting and postharvest handling activities were also observed to have more reliable information about the existing produce handling practices in farm, wholesale and retail levels. Actual farm practices have been followed without any intervention for collection of data. The extent of post-harvest loss was estimated from both sample analysis and surveyed estimation of data collected through survey.

For estimating the losses during harvesting, grading/sorting a sample of $15 \mathrm{~kg}$ fruits were drawn randomly before sorting or grading from 40 producers (10 from each kebele) at time of harvest. The sample was graded or sorted as per FAO minimum quality standards: produce must be whole, clean, free of pest damage and visible foreign matter, free of foreign smell or test and fresh in appearance. These quality standards were also used for sample analysis in case of wholesalers and retailers in order to sort and grade samples. From these samples, the extent of postharvest loss due to different causes were analyzed. During grading and sorting method, the produces which were discarded were collected and further analyzed for the causes of the postharvest loss. Digital weighing scale (hand balance) was used to measure the weight of tomato samples.

During the time of data collection, major pests and disorders were identified both in the field and laboratory through culturing the diseased samples on media. Their severity and possible impact on postharvest loss was identified during the time of field observation by inspection and interviews with respondents and key informants.

The same principle was applied for estimating the loss during loading, transportation and unloading in case of whole sellers and retailers (farm to retailer). Sample of 15 $\mathrm{kg}$ fruit was drawn randomly from ten retailers after unloading at storage and marketing place before sorting damaged produce. In case of wholesaler's sample of three wooden boxes filled with measured quantity of tomato which is used as main means of packaging for almost all value chain actors was labeled and subjected to actual handling practices and used for calculating loss from four respondents by taking $15 \mathrm{~kg}$ sample. Besides estimation by sampling, interviews with whole sellers and retailers were performed with semi-structured interview schedule. The overall data were collected are covered by the semistructured questioner.

\section{Data Analysis}

The data collected were encoded and entered into Microsoft Excel spreadsheets and IBM SPSS statistics for windows, version 20 (IBM Corp., 2011). Descriptive statistics such average, percentage standard deviation and frequency were used to analyze data and tables, graphs and charts were used to present result.

\section{Result and Discussion}

Socio-Economic Characteristics of Sample Respondents

Analysis of the socio-economic characteristics of respondents revealed the dominance of male actors across production $(86.4 \%)$ and wholesaler's level $(90 \%)$ and female actors $(73.3 \%)$ at retail level (Table 2). The average age for farmers, wholesalers and retailers was 42.35, 35.2 and 30.37 years, respectively implying that young cohort of producers, wholesalers and retailers are more involved than elder ones in tomato supply chain. It is also revealed that majorities of producers $(80.8 \%)$, wholesalers $(80 \%)$ and retailers $(70 \%)$ respond as they were married. Producers have average house hold size of 5.98 of which only 3.83 or $64 \%$ were active family size which participate in farming activities.

Almost half of producers (48\%) were illiterate which could have an effect on the adoption of appropriate agricultural technologies and skills to the farming population over the years and only $8 \%$ of them were completed secondary education. In case of wholesalers and retailers, almost all have attained minimum of primary school which showed educated youths prefer and compete for marketing of vegetables. Producers are traveling an average of $3.46 \mathrm{~km}$ in order to sell produce at first market and they were also far away from farmer training centers with an average of $1.4 \mathrm{~km}$ distance.

\section{Tomato Production Pattern}

In the study area, tomato production is largely practiced using irrigation of water pumped from ground and nearby rivers as the area has potential river water crossing most of production fields. However, majority of crop production in the district is mainly rain fed dependent. There are two major rivers (Gumera and Rib) that are of great economic importance to the district. These rivers are mainly used for irrigating horticultural crops, during the dry season. From the total, only $13.4 \%$ of producers in the area produce tomato by both rain feed and irrigation. The FGD results also showed that tomato is preferably produced during the dry season under irrigation mainly to reduce risks of diseases and pests, which enforces seasonal production. Based on information obtained from district Office of Agriculture more than 21.000 households were engaged in tomato production.

More than half of the producers $(53.60 \%)$ in the study area were able to extract their own tomato seed, while others $(43.20 \%)$ buy seeds from local market. However, majority of the producers $(61.60 \%)$, were not using new improved tomato varieties (Table 3). The average households' farm land size for crop cultivation was 1.04 ha out of which about $47.00 \%$ of farm land (0.48 ha) had irrigation access and suitable for vegetable crop production like tomato. During study period average of 0.31 ha of land $(30.11 \%)$ per house hold was under tomato cultivation which shows relative dominance of tomato over other vegetables (Figure 2). It was also estimated that more than 6.552 ha of land was covered by tomato in Fogera district and 196.560 ton of tomato was produced during the current cropping season. 
Table 2 Socio-economic characteristics of tomato value chain actors/respondents

\begin{tabular}{ll|rrr}
\hline \multicolumn{1}{c}{ Characteristics } & \multicolumn{1}{c}{ Options } & Producers & Wholesalers & Retailers \\
\hline \multirow{2}{*}{ Sex in \% } & Male & 86.40 & 90.00 & 26.70 \\
& Female & 13.60 & 10.00 & 73.30 \\
\hline Average Age & & 42.35 & 35.20 & 30.37 \\
\hline \multirow{2}{*}{ Marital status in \% } & Single & 8.80 & 20.00 & 26.70 \\
& Married & 80.80 & 80.00 & 70.00 \\
& Divorced & 10.40 & 0.00 & 3.30 \\
\hline & Illiterate & 48.00 & 0.00 & 3.30 \\
Educational level in \% & Primary school & 37.60 & 50.00 & 60.00 \\
& Secondary school & 8.00 & 50.00 & 36.70 \\
Average number of total family & Religious & 6.40 & 0.00 & 0.00 \\
Average number of active family & 5.98 & & \\
Average distance of household from FTC & 3.83 & NA & NA \\
Average distance of household from market & 3.40 & & \\
\hline
\end{tabular}

NA $=$ not applicable, FTC $=$ Farmers Training Centre

Table 3 Producers stating production practices of tomato in the study area

\begin{tabular}{l|lc}
\hline \multicolumn{1}{c|}{ Characteristics } & \multicolumn{1}{c}{ Options } & Respondents (\%) \\
\hline \multirow{2}{*}{ Purpose of tomato production } & For market only & 8.80 \\
\hline Use of trellis for tomato & For household use \& market & 91.20 \\
Use of new tomato varieties & Users & 18.40 \\
\multirow{2}{*}{ Source of seed } & Users & 38.40 \\
& Self & 53.60 \\
& Local market & 43.20 \\
\multirow{2}{*}{ Harvesting time of the day } & Office of Agriculture & 3.20 \\
& Morning & 28.26 \\
\hline \multirow{2}{*}{ Maturity stage for harvesting } & Afternoon & 59.24 \\
& Any time & 12.50 \\
\hline
\end{tabular}

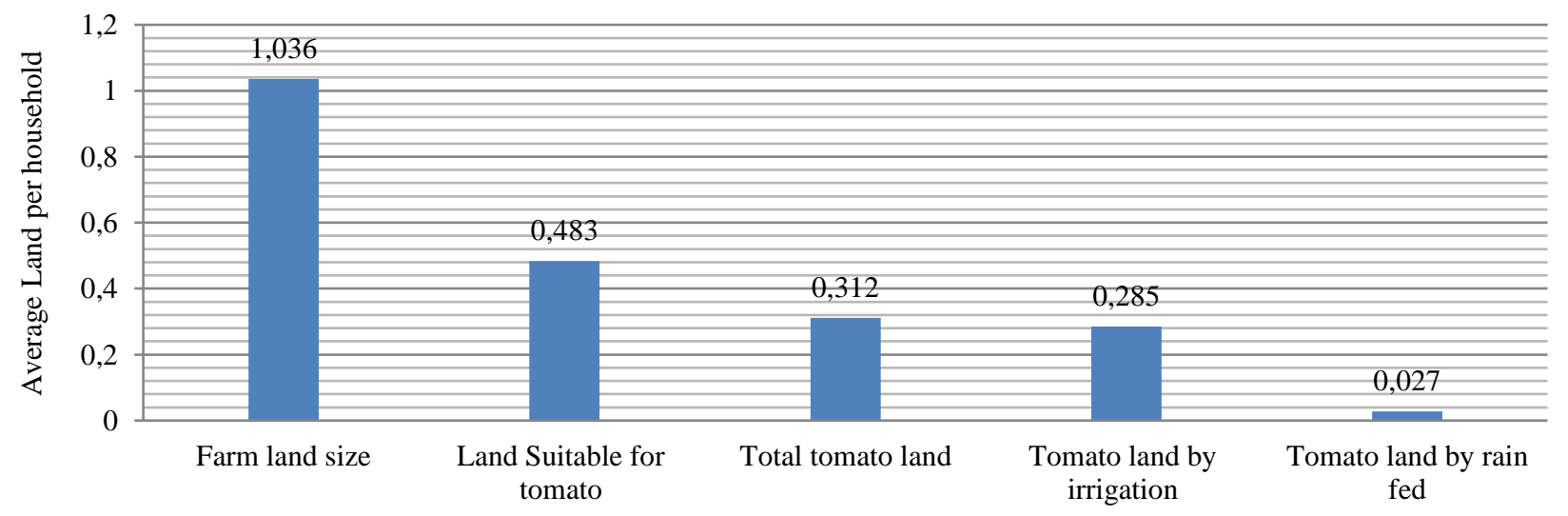

Figure 2 Average land coverage of tomato from total farm land per house hold (ha)

Majority of producers $(73.60 \%)$ harvest tomato when it reaches turning ripening stage which they assume that it is good for withstanding physical damages during long distance transportation and increasing shelf life. The remaining $(26.40 \%)$ harvest when it becomes red or fully mature for their immediate consumption and short distance marketing. With regard to harvesting time of the day, $87.20 \%$ of the producers harvest their produce during the late afternoon hours to make produce ready for next day's morning market, and $41.60 \%$ producers harvest during the early morning for nearby market. However, about $18.40 \%$ of the producers practice harvesting at any time of the day (even at mid-day with high field temperature) when there is buyer without considering possible postharvest issues and damage on produce and field plants (Table 3).

The study result reveled that majority of sample respondents have knowledge and awareness gap for production technique and use of locally available postharvest handling practice. For example, only $18.4 \%$ of producers were able to use trellis and the remaining $(81.6 \%)$ were non users, which show inability to use even simple technologies for improving production system (Table 3). 


\section{Postharvest Handling and Marketing of Tomato}

Tomato is the major vegetable crop produced for both household consumption and local market. More than half of the producers $(58.40 \%)$ store their tomato by heaping on the open field during harvesting as temporary storage, which gives chance for further sorting and selection of marketable ones but exposes product for hot and dry environment. About $45.60 \%$ of producers were using wooden box and basket for temporary storage and making harvested produce ready to transportation directly (Figure 3). This could be taken as good practice to reduce postharvest loss, though it limits the opportunity for further selection and sorting before transporting to market.

Different means are being used to transport tomato from farm to temporary storage or to the market. Majority of farmers $(95.20 \%)$ were using men's shoulder or back of women's and others used back of animals and animal drawn carts $(40.80 \%)$ to transport their tomato to the local market which in both cases may result in transportation damage (Figure 3).
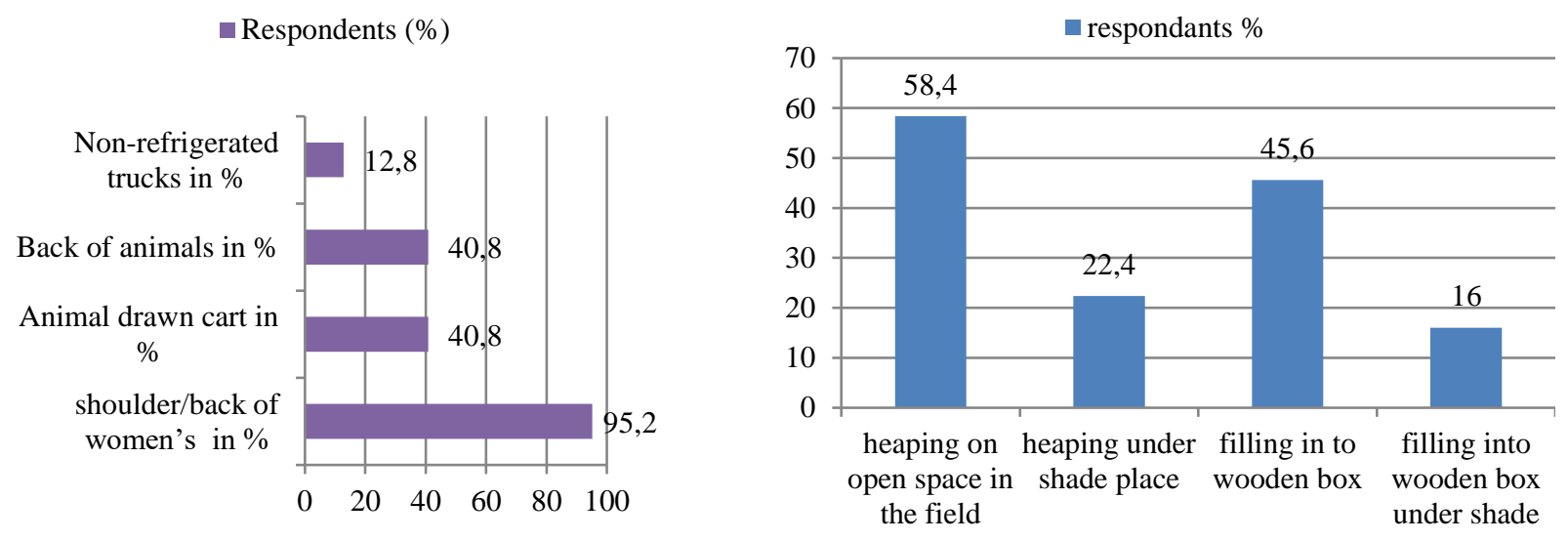

Figure 3 Percentage of respondents stating means of transportation (left) and temporary storage (right) at producers level

Farmers have various marketing actors through which they sell their produce. Most of producers $(94.40 \%)$ sell their tomato to wholesalers and others also directly sell to retailers $(55.20 \%)$ and consumers $(27.20 \%)$ by retailing at local market. During the peak harvest time and when the produce is fully matured and minor pests and diseases attacked, $78.40 \%$ of the producers were forced to sell at local market with much reduced price. During this situation, the wholesalers and retailers dtermine the price of the produce and the farmers usually do not have any choice except accepting the reduced price. In some instances, during price fall in the market, farmers hold back their produce and use for animal feed and seed extraction. This marketing trend indicates the existence of week marketing infrastructure and networking that could play a role in price stability. Bahir Dar and Gondar are the two big cities, which receive vegetables in the area, which are located at 55 and $130 \mathrm{~km}$ from Woreta (first local market for producers) town respectively. While Gondar is located in the north of Woreta, Bahir Dar is in the south.

Tomato traders buy tomato from different sources and sell to different buyers too. For example, wholesalers purchase tomato from different sources, such as from producers $(100 \%)$, local collectors $(70 \%)$ and other wholesalers $(20 \%)$, then sell to other wholesalers $(40 \%)$, retailers $(100 \%)$, consumers $(10 \%)$, and hotels or restaurants $(50 \%)$. Retailers also buy tomatoes from producers $(40 \%)$, wholesalers $(80 \%)$, local collectors $(56.70 \%)$ and they sell to consumers $(100 \%)$, small scale retailers $(16.70 \%)$ and hotels and restaurants $(54 \%)$.

During the assessment period, it was observed that majority of traders, especially retailers were simultaneously involved in handling different types of vegetables together with tomato to diversify the fresh produce for handling to maximize their returns, while most of producers were mainly engaged in tomato production as it is the most potential vegetable for the area. Mostly wholesalers were males $(90 \%)$, while most retailers were females $(73.3 \%$ ) (Table 2) since they were unable to participate in large volume purchase, which might be due to low economic status. Sharma and Singh (2011) reported that, wholesalers and retailers were involved in handling different vegetables at the same time and post harvest loss was maximum for tomato $(23.19 \%)$ relative to the other vegetables.

It was reported that, in order to contribute to marketability and diversification of tomato products, value addition attempts were carried out. In 2006, homemade tomato paste training and demonstration was performed by two women at Woreta. Likewise, tomato juice promotion was carried out in two campuses at Bahir Dar University for one week in 2007 and a total of $130 \mathrm{~kg}$ tomato was processed for juice. However, the effort was not successful since the product was new for the area and, secondly, the promotion was done just only once and did not repeated (Gebey et al., 2010).

In general, the overall marketing channel of tomato was from farmer - wholesalers/local collectors - retailers consumers and secondly farmers - retailers - consumers. Some farmers (females) also involved in retailing at small scale level and local wholesalers were also involved in collection of produce from farmers and selling to other wholesalers and retailers which come from Bahir Dar and Gondar. Large scale retailer also involve in selling both for other small scale retailers, hotels/restaurants, and consumers. The major transaction of farmers with wholesalers, local collectors and retailers in tomato was being performed from early morning till around 9 am, while mostly it was at any time in case of traders. 
Causes of Postharvest loss at Producer Level

Significant amount of postharvest loss occurred at producer's level due to complex and diverse causes as they are the main and initial actors in tomato production and marketing chain. During FGDs lack of awareness, high cost of seeds of new varieties and other agricultural inputs and producers' low economic status were raised as basic reasons for inability of the producers to use modern production and postharvest technologies. Similarly, FAO (2011) reported that the causes of PHL in low income countries are mainly connected to financial, managerial and technical limitations during production and postharvest handling.

As per the results from percentage of respondents, marketing situation $(66.40 \%)$, pest and disease $(100 \%)$ and poor quality of produce $(62.40 \%)$ were listed as major causes of post-harvest loss and quality deterioration at producer's level (Figure 4). According to Hailu and Derbew (2015) climate and weather conditions, packaging, storage and transportation facility and market situation were recorded as major causes for post-harvest loss of horticultural crops. Kiaya (2014) reported that postharvest losses may occur from improper handling, deterioration by microorganisms (fungi and bacteria) and insects.

Laboratory result revealed that Phytophthora infestans caused a postharvest loss of $3.28 \%$ as per sample analysis result. Tomato fruit worm (Helicoverpa zea) called also corn earworms and cotton bollworms attacks tomatoes and other plants and leaf miner insect forming zigzag line on leaf of tomatoes were commonly affecting tomato production in the study area which resulted in $18.25 \%$ produce loss. Postharvest diseases were also reported as one of the major causes for the postharvest loss of horticultural fresh produce across the supply chain which could be responsible for as much as $10-30 \%$ reduction in the yield of major tomato crops (Etebu et al., 2013).

Blossom end rot which is a physiological disorder caused by calcium deficiency, fruit cracking and cat face were also identified as causes of postharvest loss. Fruit cracking disorder was commonly problem for farmers experiencing high irrigation intervals. Sunburn which might be caused by excessive sun light on tomato fruit was also observed in Sembersa variety. Morphologically Sembersa variety has relatively reduced vegetative growth and most of the fruits in each plant were exposed to direct sunlight. Sample analysis showed that $2.62 \%$ of tomato loss was due to physiological disorders.

Harvesting at full ripe stage and mechanical damage during harvesting were also listed as main causes of postharvest loss of tomato at producer's level by $40.8 \%$ and $12 \%$ of respondents respectively (Figure 4 ). Both over ripe and mechanically injured fruits are usually have short shelf-life and less accepted by the consumers. Although the severe post-harvest and quality loss of horticultural crops mainly occurred during harvesting (Atanda et al., 2011), the damage is not as such clearly detectable. This hidden damage at producer's level could enhance further rotting and spoilage of produce at wholesale, retail and consumers level. Though $73.6 \%$ of producers harvested tomato when it reaches turning ripening stage, which is expected as most acceptable stage of harvest, still the contribution of late harvesting for postharvest loss is considerable (Table 3).
From Focus Group Discussions (FGDs) and field observation, it was noted that tomato quality deterioration was mainly caused by the insect borer attack and over maturity or late harvesting in order to fetch better market prices. Most of the farmers harvested at mixed ripening stage and some were practicing sorting based on ripening stage at local market when they got rejection by wholesalers and retailers. Usually green or early harvested tomato has better demand and price at the retailer and wholesalers level during time of peak production. Since wholesalers and local collectors are not willing to pay for tomatoes which are harvested at fully ripe or red maturity stage, especially at times when there is good produce supply in the area. In turn farmers usually forced to sell their produce with reduced price for local retailers and consumers. Banjaw (2017) reported that higher supply of the produce at a peak harvesting time was reasons for unsatisfactory market condition.

Since harvesting was done manually by selection, mechanical damage during harvesting time was not as such major cause of postharvest loss. However, it was observed that lack of awareness about postharvest handling existed at producer's level. As a due care was not given during harvesting tomato, daily laborers were throwing it to heaping place and even walk on top of heaped produce on the field during sorting and box filling. This could cause hidden damage on produce that might become visible and causes rotting in the shelf when produce reaches to the wholesaler and retailer. It was reported that lack of knowledge or awareness, infrastructure, and access to postharvest technologies has negatively affected the postharvest shelf life of horticultural produces (Humble and Reneby, 2014).

Educational level of farmers (Table 2) and absence of problem based training could be a contributory factor to the high postharvest losses in tomato production in the study areas. Majority of producers $(89.60 \%)$ were responded as they hadn't taken any training regarding in production and postharvest handling of tomato. It was reported that lack of awareness in perish-ability of horticultural crops, rudimentary transport methods and lack of modern storage facilities are the characteristics of the postharvest handling systems practiced in the region which increases the postharvest losses of the products. Due to these, farmers were unwillingly enforced to sell their products immediately after harvesting when there is excess supply of products at very low prices (Alemayehu et al., 2015).

More than half of producers $(58.40 \%)$ heap their tomato under open field condition where there is high field temperature and low relative humidity, while the remaining $22.40 \%$ of producers heap their tomato under shade by using available trees on the side of field or by transporting produce immediately after harvest to their home. It was reported that high temperature is well known to result in increased rates of respiration, accelerated metabolic changes and water loss in fresh produce, which eventually leading to reduced market and nutritional quality (Kitinoja and AlHassan, 2012).

Since more than $40 \%$ of producers use animal drown carts and back of animals for transporting harvested produce, animal fall at road was causing tremendous transportation damage and loss which could enhance further bruising and rotting of tomato when they took to the 
traders (Figure 3). It was also noted that the use of animal transportation could be considered as major cause of postharvest loss as it might expose produce to physical injury as a result of abrasion damage. Poor quality equipment and materials usage during handling was reported to cause tremendous mechanical, physiological and pathological damages on horticultural crops (Kasso and Bekele, 2016). Alemayehu et al. (2015) also reported that farmers transported their produces in sacks, baskets, in some extent using wooden and plastic containers on back of animals or human labor might exposed the products to direct sunlight and mechanical damages.

More than $65 \%$ of producers responded as they faced problem of price fall and absence of market at all in some cases, which was becoming reason for late harvesting and poor harvesting and handling practice (Figure 4). Distant market, low price, lack of proper means of transportation and unsuitable of road were identified as discouraging factors for postharvest chain of horticultural crops (Kasso and Bekele, 2016). In line with these FGD result showed that market condition was also the major discouraging problem and causes of postharvest loss for tomato.

Most of the farmers responded as they sold their produce at nearby market and a few of them also sold on farm. Price for tomato was not satisfactory for producers, mainly because of higher supply of the produce at a peak harvesting time. This was also main reason for price fall at peak time. Seasonality of production and fluctuations in the supply of fresh tomatoes leading to market superfluity during on-season and shortage during off season was reported in many producer countries worldwide and Africa including Ethiopia, Kenya, Nigeria, Nepal and India (Getahun and Habte, 2017).

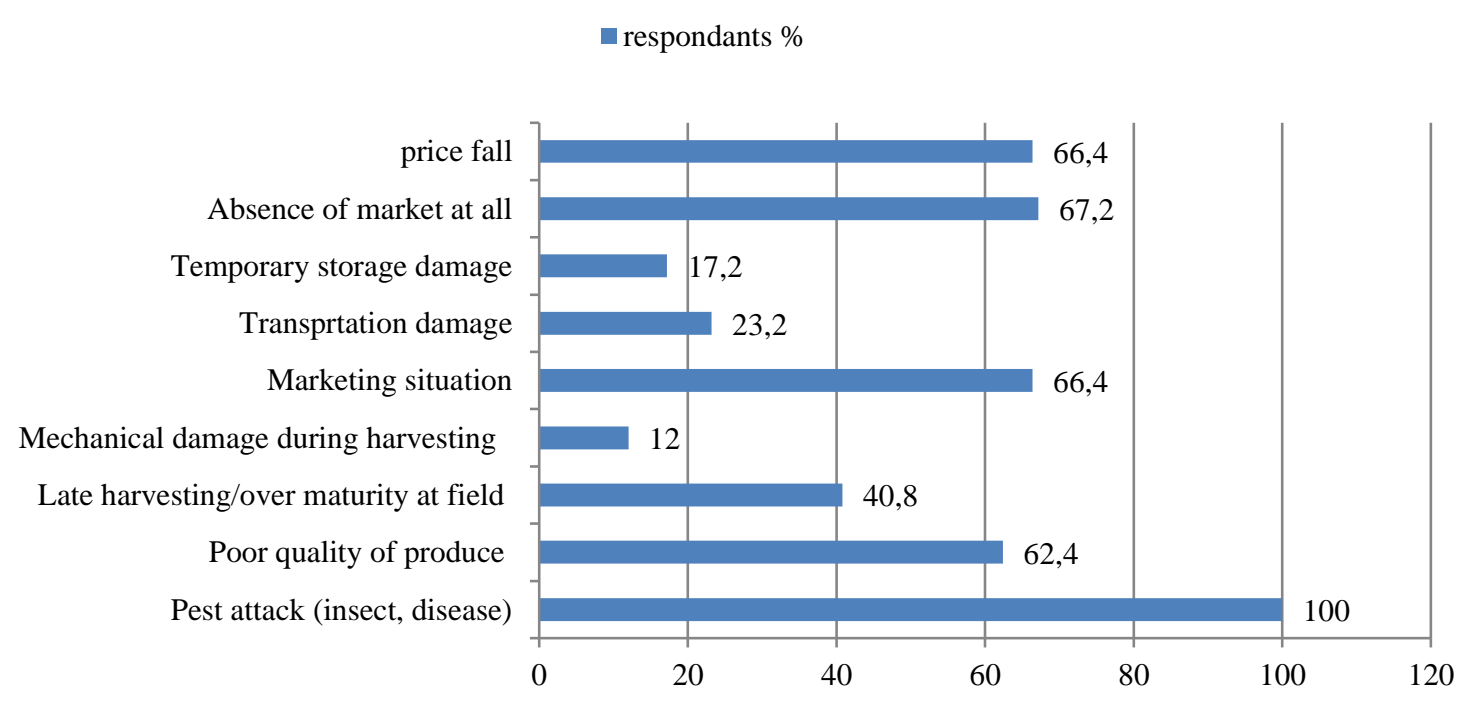

Figure 4 Major causes of postharvest loss and percentage of respondents at producer's level

Table 4 Respondents stating factors making producers not to be benefited

\begin{tabular}{l|cccc}
\hline \multicolumn{1}{c|}{ Factors } & Wholesalers (\%) & Rank & Retailers \% & Rank \\
\hline Price fall & 90.00 & 1 & 43.30 & 3 \\
Uniform harvesting period & 80.00 & 2 & 60.00 & 1 \\
Insect pest and disease problem & 70.00 & 3 & 56.70 & 2 \\
Lack of access for market place & 50.00 & 4 & 36.70 & 4 \\
Poor quality of produce & 40.00 & 5 & 43.30 & 3 \\
Weak market organization & 40.00 & 5 & 23.30 & 5 \\
Bargaining power of intermediaries & 30.00 & 6 & 23.30 & 5 \\
\hline
\end{tabular}

Eighty percent of wholesalers pointed out that most of the producers are not as such benefited due to many challenges in tomato production and marketing chain. Among the major reasons, they listed "lack of access for market place $(50 \%)$, uniform harvesting period $(80 \%)$, quality of produce $(40 \%)$, price fall $(90 \%)$, pest and disease problem $(70 \%)$, bargaining power of intermediaries $(30 \%)$ and weak market organization (40\%)" as shown in the Table 4. It was reported tha, interference of brokers is still affecting the benefit of the producers in case of Fogera district (Gebey et al., 2010).

These factors were also suggested by retailers as major challenges that made farmer's non beneficiary from tomato production and marketing. Price paid for producers for their produce was also not satisfactory relative to other actors in tomato marketing chain. This indicates a need of special attention to the producers in improving overall production, postharvest handling and marketing network. Hussen et al. (2013) also reported that horticulture products in Ethiopia are mainly produced by smallholder farms and most of the farmers sell their products at a nearby market and a few sell both on farm and in nearby market such that the marketing condition is unsatisfactory and discouraging. The major factors were listed with their rank in the Table 4 below. 


\section{Causes of Postharvest Loss at Traders Level}

As identified by wholesalers and retailers, poor marketing access, reduced price of produce, damage during transport, damage during storage, low quality of produce, climatic condition, physical damage during harvesting, late harvesting and poor packaging material were listed as major causes of tomato postharvest loss. These all causes of postharvest loss are not single or separate factors, rather they were interrelated and complex in nature. For example harvesting damage at producer's level could be reason for low quality of produce and storage loss when produce reaches wholesaler and retail market.

Hidden damage during harvesting and transportation was also stated as reason for postharvest loss by $16.70 \%$ of retailers and $40 \%$ of wholesalers. Harvesting and transportation damage at producer level causes rotting and further spoilage of produce at retailers $(60 \%)$ than wholesalers $(40 \%)$ as they store for more time for retailing. Wholesalers transfer produce to next chain within average of 3.90 days, while retailers store average of 5.40 days up to finishing all purchased. Kiaya (2014) reported that food losses are mainly due to poor infrastructure and logistics, lack of technology, insufficient skill, knowledge and management capacity of supply chain actors and lack to markets.

Niguse (2018) reported that damage assessment result at wholesale showed maximum damage for tomatoes than other vegetables. Delayed harvesting was stated as major cause of loss as it enhances crop susceptibility for handling damage and reduces shelf life. Tomato is reported as a very sensitive crop and cannot be stored for even short period if it is fully ripe (Singh et al., 2013). Tomatoes harvested red ripe experienced much higher PHL than tomatoes harvested at the breaker or turning stage of maturity when measured using the same sampling loss assessment methods on the farm, at wholesale and retail markets (WFLO, 2010). During the assessment period, it was also observed that all trade actors have sanitation problem both at the market and temporary storage rooms which might enhance further rotting and deterioration of tomato before selling. The major reasons which were stated at trader's level for postharvest loss of tomato were listed in Table 5.

Table 5 Proportion of wholesalers and retailers stating reasons for loss of tomato

\begin{tabular}{l|rrrc}
\hline \multicolumn{1}{c|}{ Reasons for postharvest loss } & Wholesalers \% & Rank & Retailers \% & Rank \\
\hline Damage during transportation & 100.00 & 1 & 100.00 & 1 \\
Storage damage & 90.00 & 2 & 90.00 & 2 \\
Climatic condition & 80.00 & 3 & 53.30 & 5 \\
Absence of market & 70.00 & 4 & 50.00 & 6 \\
Delayed harvesting & 70.00 & 4 & 63.30 & 3 \\
Price fall/low price & 50.00 & 5 & 53.30 & 5 \\
Poor quality of produce & 50.00 & 5 & 40.00 & 7 \\
Harvesting damage & 40.00 & 6 & 60.00 & 4 \\
Absence of road for trucks & 40.00 & 6 & 20.00 & 9 \\
Poor packaging material & 20.00 & 7 & 30.00 & 8 \\
\hline
\end{tabular}

Due to the price fluctuation in the market, sometimes retailers have to hold back their produce and some of them also sale with reduced price or even discard when no more buyers come. This is commonly case for these who participate in small scale retailing of fully matured and low quality produce at open market. Banjaw (2017) also reported that different containers such as wooden box, baskets, plastic materials and sacks used in handling of produce with inadequate handling that enhances level of produce damage. Price deduction was major problem for all production and distribution actors in tomato marketing. At wholesale and retailers market, average of $35.5 \%$ and $28.33 \%$ price discount was estimated respectively depending on degree of quality losses of produce.

\section{Extent of Postharvest Loss from Respondents Estimation}

As per producer estimation, the extent of loss was $21.24 \%$ before reaching wholesalers or local collectors due to complex and diversified factors discussed above. All farmers responded as "they experience minimum of 5\% and maximum of $40 \%$ postharvest loss with mean value of $21.24 \%$ and standard deviation of 6.8 ". The extent of loss was estimated as the difference between quantity harvested and quantity sold in relation to total quantity harvested at producer's level. Hailu and Derbew (2015) reviewed that postharvest losses in fresh perishables are 5 to $35 \%$ in developed countries and 20 to $50 \%$ in developing countries.
Tomato traders also experienced huge loss during transportation, storage and marketing. As per their estimation, average of $11.60 \%$ and $12.13 \%$ of tomato was lost at wholesalers and retailers level, respectively (Table 6). This result showed that about quarter of tomato purchased from producers was not able to reach consumers. Similarly, according to Kasso and Bekele (2016), post-harvest loss ranging from $20 \%$ to $50 \%$ was recorded for fruits and vegetables in between marketing and consumption due to lack of appropriate management during harvesting, packaging, storage, grading and transportation.

During assessment period, it was also observed that few farmers left their tomato in the field without harvesting during time of peak harvest as the price is very low. They responded that the price at that period was even unable to cover cost of daily laborers for harvesting, although this situation was seen only at peak harvesting period. This showed that extent of loss might be above their actual estimation, although some of them practiced seed extraction and used as animal feed when rejected at market.

At retailer level, postharvest loss of tomato was relatively high. This might be due their practices to store the produce for long time up to final retailing. Average time of storage for retailers was 5.40 days after the produces reached on their hand. Kumar et al. (2006) reported that retailer in the process of marketing retained 
the produce for a longer period than that of the wholesaler. As a result, the postharvest loss at the retail level was relatively more as compared to wholesale level. Pair means test or $\mathrm{t}$ test result (Table 6) showed that transportation loss at wholesale level is significantly higher than at retailers' level. This might be due to mechanical damage that occurs during long distance transportation and the highest amount they handle.

\section{Extent of Postharvest Loss from Sample Analysis}

The result indicated that total postharvest losses of $24.17,5.24$ and $8.17 \%$ were occurred at farmers, wholesalers, and retailer's level, respectively (Table 7). At farmer level, this loss was mainly due to pest (borer), disease and physiological disorders causing 18.25, 3.28, and $2.62 \%$ of postharvest loss respectively. In case of traders, loss was mainly due to transportation damage and rotting in the storage. Wholesalers experienced relatively low loss which might be due to only one turn handling that reduces contact frequency with produce. Kumar et al. (2006) reported that maximum postharvest loss of potato and onion was observed at farm level and it was about $60 \%$ of total postharvest loss.

Farmers level sample analysis showed relatively higher postharvest loss $(24.17 \%)$ than respondent's estimation (21.24\%) which might be due to some farmers practiced household consumption, seed extraction and animal feed when tomato was mechanically damaged and over ripened. However, in case of wholesalers extent of loss was reduced by half in sample analysis than their actual respondent's estimation which might be due to exaggeration of their loss estimation. Sample analysis result of retailers was also less than estimation value, which might be due to produce discard if not sold, was not considered in sample analysis.

Table 6 Amount of loss (\%) at trader's level as per their estimation

\begin{tabular}{l|ccccccccc}
\hline \multirow{1}{*}{$\begin{array}{c}\text { Agents } \\
\text { Stage of loss }\end{array}$} & \multicolumn{4}{|c}{ Wholesaler $(\mathrm{N}=10)$} & \multicolumn{3}{c}{ Retailers $(\mathrm{N}=30)$} & \multirow{2}{*}{ T value } \\
\cline { 2 - 10 }$n$ & Min & Max & Mean & St. Dev. & Min & Max & Mean & St. Dev. & $2.204^{* *}$ \\
Transportation & 5 & 10 & 6.70 & 2.34 & 3 & 10 & 4.80 & 1.77 & 0.974 \\
Storage & 2 & 10 & 4.90 & 2.13 & 3 & 15 & 7.33 & 2.96 & 0.732 \\
Total & 7 & 15 & 11.60 & 2.95 & 8 & 21 & 12.13 & 3.41 & 0.13 \\
\hline
\end{tabular}

Losses were estimated as the difference between quantity purchased and quantity sold in relation to total quantity purchased. $* *$ shows significant difference $\mathrm{b} / \mathrm{n}$ means at $5 \%$.

Table 7 Extent of loss (\%) from sample analysis

\begin{tabular}{l|rrrrrr}
\multicolumn{1}{c}{ Actors in chain } & \multicolumn{2}{c}{ Producers $\left(\mathrm{N}=10^{*} 4\right)$} & \multicolumn{2}{c}{ Wholesaler $(\mathrm{N}=4 * 3)$} & \multicolumn{2}{c}{ Retailers $(\mathrm{N}=10)$} \\
\hline Measurement Types & \multicolumn{1}{c}{ Mean } & Std. Dev. & \multicolumn{1}{c}{ Mean } & Std. Dev. & \multicolumn{1}{c}{ Mean } & Std. Dev. \\
\hline Marketable in kg & 11.37 & 1.25 & 14.16 & 7.13 & 13.77 & 0.70 \\
Unmarketable in kg & 3.62 & 1.25 & 0.84 & 2.41 & 1.23 & 0.70 \\
Loss in \% & 24.17 & 8.36 & 5.60 & 2.23 & 8.17 & 4.68 \\
\hline
\end{tabular}

The "t value" or "pair mean test" for producer with wholesaler, producer with retailer and wholesaler with retailer is $8.826^{* * *}, 6.977^{* * *}$, and $4.811^{* * *}$ respectively.

Table 8 Amount of price deduction (\%) for tomato marketing actors as per their estimation

\begin{tabular}{l|cccc}
\hline \multicolumn{1}{c|}{ Major actors of chain } & Min. & Max. & Mean & Std. Dev. \\
\hline Producers & 20.00 & 70.00 & 43.64 & 16.43 \\
Wholesalers & 20.00 & 50.00 & 35.50 & 11.89 \\
Retailers & 0.00 & 60.00 & 28.33 & 16.88 \\
\hline
\end{tabular}

The " $\mathrm{t}$ " value or "pair mean test" for producer with wholesaler, producer with retailer and wholesaler with retailer is $3.708^{* * *}, 4.524 * * *$, and $0.737^{\mathrm{ns}}$ respectively.

In general, extent of postharvest loss for tomato was found to be almost half, which is too huge and it would be also above this if consumer level loss is considered. Kitinoja and AlHassen (2012) reported that with postharvest losses at the farm, wholesale and retail markets commonly reaching $30 \%$ to $50 \%$ for many of the horticultural crops, and physical damage measuring as high as $50 \%$ to $89 \%$ of loss for vegetable crops in the markets of Africa and India. This represents an enormous waste especially at farmers' level. Kasso and Bekele (2016) also reported that the highest post-harvest loss was recorded in tomato (45.32\%) than other vegetables and fruits. Sample analysis result showed that producer experience maximum amount of tomato loss which is significant with both wholesalers and retailers. Extent of loss at retail level was also significantly greater than wholesale level as shown in the Table 7 below.

Farmers experience price deduction up to $43.64 \%$ due to absence of market, poor quality of produce, over maturity and high supply at peak harvesting time. The following table (Table 8) shows estimated price deduction at actors' level as per their estimation. The result indicated that producers experience the highest and significant price deduction than both wholesalers and retailers. Wholesalers and retailers were faced problem of price deduction though it is statistically non-significant between them.

\section{Conclusion}

In the study area, tomato is preferably produced during the dry season under irrigation mainly to reduce risk of diseases and pests which enforces seasonal production. Significant postharvest losses occur along the tomato supply chain. Farmers were experiencing huge amount of PHL loss of 21.24 and $24.17 \%$ as per their estimation and results of sample analysis, respectively. As per their estimation, average of $11.6 \%$ and $12.13 \%$ of tomato was lost at wholesalers and retailers level, respectively. 
Similarly, sample analysis at trader's level also showed existence of loss, although extent was relatively lower than estimation result of sample respondents. The causes of PHL are complex and varied so that there is no one solution that is appropriate in all cases.

Marketing situation, pest and disease, lack of awareness in postharvest handling and marketing, high cost of seeds of new varieties, producers' low economic status, late harvesting, mechanical damage during harvesting and transportation, poor quality of produce, price fall and absence of market at all were listed as major causes of post-harvest loss and quality deterioration of tomato at producer's level.

\section{Acknowledgment}

The authors would like to thank to University of Gondar for financial support and staff of Woreta Office of Agriculture for their assistant in selecting sample respondents.

\section{References}

Alemayehu M, Tessafa F, Bizuayehu S, Ayele B. 2015. Amhara Region Horticulture Development Strategy (2015-2019). Agro-Big, Bahir Dar, Ethiopia. URL: https://www.agrobig.org/documents/7.1_Amhara_Region_H orticulture_Development_Strategy_2015-2019.pdf. Accessed on January 20, 2018.

Atanda SA, Pessu PO, Agoda S, Isong IU, Ikotun I. 2011. The Concepts and Problems of Postharvest Food Losses in Perishable Crops. Afr. J. Food Sci. 5 (11): 603-613.

Ayandiji A, Adeniyi R, Omidiji D. 2011. Determinant Post Harvest Losses among Tomato Farmers in Imeko-Afon Local Government Area of Ogun State, Nigeria. Glob. J. Sci. Front. Res. 11(5): 23-28.

Banjaw TD. 2017. Review of post-harvest loss of horticultural crops in Ethiopia, its causes and mitigation strategies. J. Plant Sci. Agric. Res. 2(1):006.

Cochran, WG. 1977. Sampling Techniques ( $3^{\text {rd }}$ ed.). New York: John Wiley \& Sons.

Emana B, Afari-Sefa V, Nenguwo N, Ayana A, Kebede D, Mohammed H. 2017. Characterization of pre- and postharvest losses of tomato supply chain in Ethiopia. Agric. \& Food Secur. 6(3): 1-11, doi: https://doi.org/10.1186/s40066-016-0085-1

Etebu E, Nwauzoma AB, Bawo DDS. 2013. Postharvest spoilage of tomato (Lycopersicon esculentum Mill.) and control strategies in Nigeria. J. Biol. Agric. \& Healthcare, 3(10): 5162.

FAO (Food and Agriculture Organization). 2011. Global food losses and food waste - Extent, causes and prevention. Rome, Italy.

FAO (Food and Agriculture Organization). 2016. Opportunities for local and regional authorities in facilitating food waste prevention and reduction. Global Initiatives on Food Loss and Waste Reduction. Brussels, Belgium.

FDOA (Fogera District Office Agriculture). 2016. Annual report on agriculture production and area coverage. Woreta, Office of Agriculture, Woreta, Ethiopia.
Gebey T, Berhe K, Hoekstra D. 2010. Vegetables value chain development in Fogera district: Experiences from IPMS project interventions. IPMS Ethiopia.

Getahun D, Habte B. 2017. Experiences of rain-fed tomato production in an open field. Int. J. Sci. and Res. 6(2): 13351343.

Hailu G, Derbew B. 2015. Extent, causes and reduction strategies of postharvest losses of fresh fruits and vegetables. Review. J. Biol. Agric and Healthcare, 5(5): 49-64.

Humble S, Reneby A. 2014. Post-harvest losses in fruit supply chains-A case study of mango and avocado in Ethiopia. Msc. thesis, Swedish University of Agricultural Sciences.

Hussen S, Beshir H, Woldehawariyat Y. 2013. Postharvest loss assessment of commercial horticultural crops in South Wollo, Ethiopia "challenges and opportunities". Food Science and Quality Management, 17: 34-39.

IBM Corp. 2011. IBM SPSS Statistics for Windows, Version 20.0. Armonk, NY: IBM Corp.

Kaminski J, Christiaensen L. 2014. Post-harvest loss in SubSaharan Africa-what do farmers say? Glob. Food Secur. 3(34): 149-158. doi: http://dx.doi.org/10.1016/j.gfs.2014.10.002

Kasso M, Bekele A. 2016. Post-harvest loss and quality deterioration of horticultural crops in Dire Dawa Region, Ethiopia. J. Saudi Soci. Agric. Sci. 17: 88-96. doi: http://doi.org/10.1016/j.jssas.2016.01.005

Kiaya V. 2014. Post-harvest losses and strategies to reduce them. Technical paper on postharvest loss, scientific \& technical department, Action Contre la Faim (ACF) International, p. 25.

Kitinoja L, AlHassan HY. 2012. Identification of appropriate postharvest technologies for small scale horticultural farmers and marketers in Sub-Saharan Africa and South Asia: Part 1. Postharvest losses and quality assessments. Act. Hort. 934: $31-40$.

Kumar DK, Basavaraja H, Mahajanshetti SB. 2006. An Economic Analysis of Post-Harvest Losses in Vegetables in Karnataka Kumar. Ind. J. Agri. Econ. 61(1): 134-146.

Macheka L, Spelt E, Van der Vorst JGAJ, Luning PA. 2017. Exploration of logistics and quality control activities in view of context characteristics and postharvest losses in fresh produce chains: case study for tomatoes. Food Control, 77: 221-234. doi: http://doi.org/10.1016/j.foodcont.2017.02.037

Niguse B. 2018. Assess and prioritize problems related postharvest management of horticultural crops in Jimma Town, in Bishishe Market. J. Biodivers. Biopros. Dev. 5(1): 168. doi: http://doi.org/10.4172/2376-0214.1000168

Sharma G, Singh S. 2011. Economic analysis of post-harvest losses in marketing of vegetables in Uttarakhand. Agric. Econ. Res. Rev. 24: 309-315.

Singh AK, Singh N, Singh, BB. 2013. Marketing and postharvest loss assessment of vegetables in Varanasi district (U.P.). Internat. Res. J. Agric. Eco. \& Stat. 4 (1): 47-50.

Vilariño MV, Franco C, Quarrington C. 2017. Food loss and waste reduction as an integral part of a circular economy. Front. Environ. Sci. 5: 21. doi: https://doi.org/10.3389/fenvs.2017.00021

WFLO (World Food and Logistics Organization). 2010. Identification of appropriate postharvest technologies for improving market access and incomes for small horticultural farmers in Sub-Saharan Africa and South Asia. WFLO Grant Final Report to the Bill \& Melinda Gates Foundation. p. 318. 